\title{
Larval connectivity of pearl oyster through biophysical modelling; evidence of food limitation and broodstock effect
}

\author{
Yoann Thomas ${ }^{\text {a, }}{ }^{*}$, Franck Dumas ${ }^{b}$, Serge Andréfouët ${ }^{a}$ \\ a UMR-9220 ENTROPIE, (Institut de Recherche pour le Développement, Université de la Réunion, CNRS), Laboratoire d'Excellence CORAIL, 101, promenade \\ Roger-Laroque Anse Vata, BP A5, 98848 Noumea, New Caledonia \\ b Ifremer, Unité DYNECO, Z.I. de la Pointe du Diable, CS 10070, 29280 Plouzané, France
}

\section{A R T I C L E I N F O}

Article history:

Received 30 June 2015

Received in revised form 10 February 2016

Accepted 20 March 2016

Available online 21 March 2016

\section{Keywords:}

Pearl oyster

Lagoon

Biophysical modelling

Connectivity

Population dynamics

DEB model

\begin{abstract}
A B S T R A C T
The black-lip pearl oyster (Pinctada margaritifera) is cultured extensively to produce black pearls, especially in French Polynesia atoll lagoons. This aquaculture relies on spat collection, a process that experiences spatial and temporal variability and needs to be optimized by understanding which factors influence recruitment. Here, we investigate the sensitivity of $P$. margaritifera larval dispersal to both physical and biological factors in the lagoon of Ahe atoll. Coupling a validated 3D larval dispersal model, a bioenergetics larval growth model following the Dynamic Energy Budget (DEB) theory, and a population dynamics model, the variability of lagoon-scale connectivity patterns and recruitment potential is investigated. The relative contribution of reared and wild broodstock to the lagoon-scale recruitment potential is also investigated. Sensitivity analyses pointed out the major effect of the broodstock population structure as well as the sensitivity to larval mortality rate and inter-individual growth variability to larval supply and to the subsequent settlement potential. The application of the growth model clarifies how trophic conditions determine the larval supply and connectivity patterns. These results provide new cues to understand the dynamics of bottom-dwelling populations in atoll lagoons, their recruitment, and discuss how to take advantage of these findings and numerical models for pearl oyster management.
\end{abstract}

(c) 2016 Elsevier Ltd. All rights reserved.

\section{Introduction}

The extensive fishing pressure and aquaculture demand worldwide reinforces the need to understand recruitment dynamics for enhanced resource management. In marine ecosystems, larval recruitment is a critical process for the maintenance and resilience of populations which are submitted to multiple stressors and hazards, both pre- and post-settlement (Eckman, 1996; Pineda, 2000). Knowledge of recruitment is challenging for the management of marine area and species conservation, but is definitely a high priority. Recently, coupled biophysical models have proved to be suitable tools for the conservation, management and recovery of marine species stocks (Hinrichsen et al., 2011; Kim et al., 2013). Modelling approaches benefit from technological developments and enhanced computation power, which allows exploring a large amount of hypotheses at various spatial and temporal resolutions.

\footnotetext{
* Corresponding author. Present address: Ifremer, Unité DYNECO/LEBCO, Z.I. de la Pointe du Diable, CS 10070, 29280 Plouzané, France

E-mail address: yoann.thomas1@gmail.com (Y. Thomas).
}

As such, the development of models is useful to study the relative effects of the physical, biological and behavioural variables and their interactions on recruitment variability. For instance, models have helped assessing the relative effects of larval behaviour, pelagic larval duration (PLD), hydrodynamics and broodstock location for bottom-dwelling species (e.g. North et al., 2008; Kim et al., 2010; Thomas et al., 2014). Depending on the coastal location (extent, bathymetry, degree of openness, tidal regime, weather conditions) and species considered (PLD, behaviour), the contribution of the biophysical variables to the larval dispersal and recruitment patterns will likely be different (Nicolle et al., 2013).

Despite its potential, modelling is not trivial, and to understand mechanistically the recruitment patterns, it is necessary to reduce the complexity of the system by focusing first on the core processes (Pineda et al., 2009). The larval supply, larval dynamics (including growth, dispersal and mortality), settlement and post-settlement factors are the main drivers of benthic species recruitment (Metaxas and Saunders, 2009). To be able to accurately predict recruitment, we need to correctly parameterize these processes at the right temporal and spatial scales. In French Polynesia, pearl culture relies entirely on the supply of wild juveniles of only one 
species Pinctada margaritifera, collected on artificial substrates. Hatchery production currently provides only a marginal proportion of the spat production. In the French Polynesian archipelagos, the pearl culture spread in 27 atolls and islands, among which 15 developed only a spat collecting activity. However, the pearl oyster producers have experienced variable success rates, with significant spatial and temporal variability in spat supply, both within and between lagoons (Thomas et al., 2012a). This uncertain process has a number of ecological, economical and societal consequences in Polynesian lagoons. For instance, spat's supply variability led the producers to increase the density of collectors to achieve a minimum success rate, which generates a large amount of derelict gears and plastic pollution. (Andréfouët et al., 2014). Moreover, poor spat production increases inter-lagoon transfers. In addition to higher costs for farmers, these transfers have been responsible for the spread of epibiotic species and pathogens. For all these reasons, an intensive research effort has been undertaken since 2009 to model accurately spat collection and understand its variability, with in fine the development of spatially-explicit management tools (e.g., Andréfouët et al., 2012; Thomas et al., 2014). As such, in situ studies recently described the multi-scale variability of pearl oyster's larval dispersal and spat collection (Thomas et al., 2012a) and concurrent research designed and validated a 3D larval dispersal model integrating an empirical behavioural sub-model (Dumas et al., 2012; Thomas et al., 2012b, 2014). These studies highlighted the heterogeneous pathways of larval connectivity in the Ahe atoll lagoon and a strong effect of the PLD was empirically evidenced.

The heterogeneity of environmental parameters and food availability can affect development, metamorphosis success and survival of the larvae, especially by slowing down its growth, which itself can increase predation risks (Hofmann et al., 2004). To better understand the consequences of environmental heterogeneity on pearl oyster larval development, a bioenergetics model following the Dynamic Energy Budget (DEB) theory has been parameterized and validated (Thomas et al., 2011). The DEB model offers a generic framework to describe the energy flow through an organism in its environment (Kooijman, 2010). It covers the full life cycle of an individual and provides quantitative information on mass and energy balances. In Ahe atoll, the DEB model allowed quantifying the consequences of heterogeneity in food source and thermal conditions on larval growth, and also showed the potential consequences of food limitation (Thomas et al., 2011). The next logical step was to couple the 3D connectivity model with the DEB model in order to evaluate how larvae could simultaneously grow and disperse under realistic environmental conditions.

This study reports for Ahe atoll lagoon the connectivity results achieved when coupling the 3D larval Lagrangian dispersal model with the DEB model used to control the growth of each larvae. The larval supply, mortality and settlement processes were added in a population dynamics module to realistically estimate and compare the settlement potential. In addition, since previous studies have shown how the broodstock location determine larval connectivity (Thomas et al., 2014), the recent assessment of the Ahe atoll oyster standing stock by Andréfouët et al. (2016) was also used here in conjunction with the reared stock to achieve a more realistic model.

\section{Materials and methods}

\subsection{Study area}

Ahe atoll is located in the northwestern part of the Tuamotu Archipelago, in French Polynesia ( $14^{\circ} 48^{\prime} \mathrm{S}-146^{\circ} 30^{\prime} \mathrm{W}$; Fig. 1a). The lagoon is an almost closed water body of $142-\mathrm{km}^{2}$ connected to the ocean through a 11-m deep, 200-m wide, pass located in the northwest side of the atoll rim, and with a low ratio of functional reef flats and spillways along the southern and northwestern side of the rim (Andréfouët et al., 2001). Ahe is much deeper than most atolls previously investigated in French Polynesia with an average depth of $41 \mathrm{~m}$, reaching up to $70 \mathrm{~m}$ depth. The lagoon bathymetry was mapped after interpolation of tide-corrected acoustic tracks. The deeper areas are made of honeycomb-like cellular structures and the southwestern part of the lagoon is much shallower than the rest of the lagoon.

\subsection{The biophysical model}

The biophysical model combined a transport model with a vertical swimming sub-model to account for larval behaviour, and a bioenergetics growth model simulating the larval growth. A population dynamics model was applied in post processing in order to account for the larval supply, mortality and settlement processes, and then compute the spatio-temporal settlement potential.

\subsubsection{The larval transport model}

Larval transport was simulated with the 3-D hydrodynamic model MARS3D (Lazure and Dumas, 2008). A full description of the hydrodynamic model implementation and its validation can be found in Dumas et al. (2012) and first applications to larval transport modelling are reported by Thomas et al. (2012b, 2014). The model horizontal cell size was $100 \mathrm{~m}$ by $100 \mathrm{~m}$. The vertical resolution included 23 sigma-vertical layers tightened close to the bottom and to the surface in order to better catch the bottom and surface boundary layers. The hydrodynamic model is coupled with a lagrangian advection/dispersal module. The lagrangian vertical dispersion was computed thanks to a non-naïve random walk procedure following Visser (1997). Besides, the lagrangian model mimicked the larvae dial vertical migration by adding a swimming velocity: a positive velocity (going up) during the night and a negative velocity (going down) during the day, following a sinusoid signal (Thomas et al., 2012b). Thus, larval trajectories were simulated in three dimensions through advection diffusion and by the vertical swimming displacement.

At the initial $\mathrm{t}=0$ state, 12 particles were released in each grid cell into the lagoon (4 particles at 3 depth levels: 5, 6 and $7 \mathrm{~m}$ depth), giving a total number of 166,692 particles released.

\subsubsection{The larval growth model}

The Dynamics Energy Budget (DEB) model used to simulate the larval growth was derived from the standard DEB model described by Kooijman (2010). The model equations and parameter values were based on the study performed by Thomas et al. (2011). The DEB model differentiates three life stages: the embryo, which does not feed nor reproduce; the juvenile, which eats but does not reproduce; and the adult, which eats and reproduces. The larval stage corresponded to the DEB juvenile life stage. The dynamics of three state variables were described: the energy allocated to build the somatic tissues $E_{V}$, the reserve energy $E$, and the energy allocated to development to reach adulthood $E_{R}$, which corresponded to the extra energy needed to achieve complexity (e.g. development of the eye spot, foot or gills). The state variables dynamics depended on two forcing variables: the food concentration and the water temperature. As described by Thomas et al. (2011), we used in vivo chlorophyll-a measurements as food source (see following section) and in situ temperature.

The 3D Lagrangian transport model and DEB model were coupled by simulating the DEB state variables (i.e., E, $E_{V}$ and $E_{R}$ ) dynamics for each particle released, according to the trophic and thermal conditions found by this particle during its advection, diffusion and behaviour.

The DEB model simulated the growth of a mean individual. In 

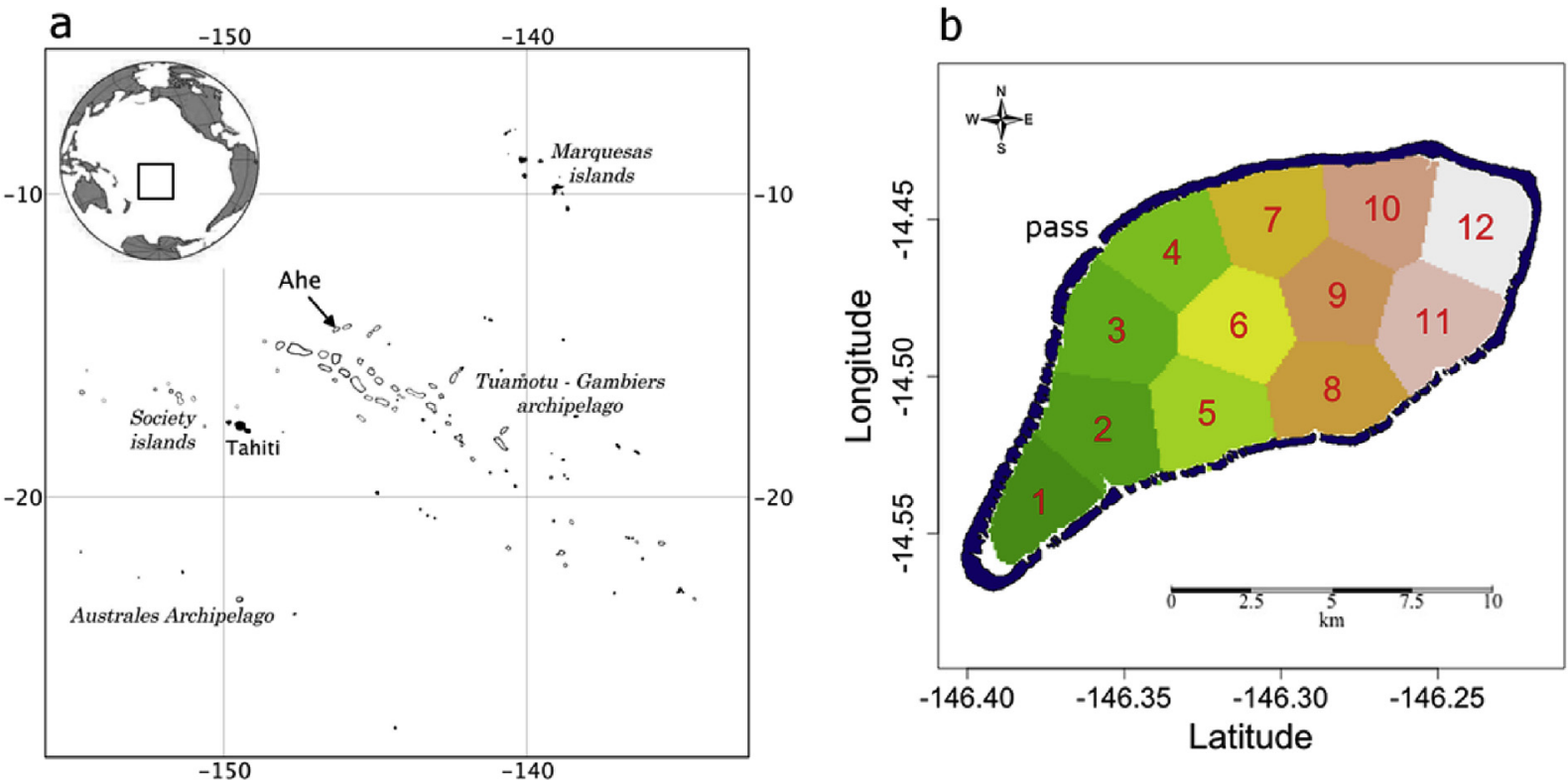

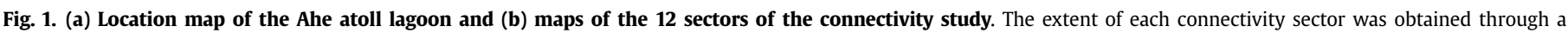

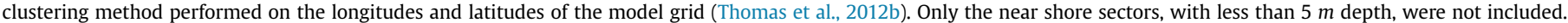
Numbers identify the spawning sites and destination locations described in the results section.

order to take into account the inter-individual growth variability, we calculated a standard deviation $\left(\sigma_{L}\right)$ at each time step corresponding to $15 \%$ of the mean length simulated. This inter-individual size-dependent percentage has been estimated from in situ growth data obtained experimentally and from the sampling of a wild cohort (Thomas et al., 2011). This allowed computing the probability $(P)$ that larvae of mean length $(L)$ reached the competent stage, defined by a length threshold $\left(L_{f i x}\right)$ :

$P\left(L \geq L_{f i x}\right)=1-\int_{-\infty}^{L_{f i x}} f_{X}(L) \mathrm{d} x$

with

$f_{X}(L)=\frac{1}{\sqrt{2 \pi} \sigma_{L}} e^{-\frac{\left(L-L_{f i x}\right)^{2}}{2 \sigma_{L}}}$

\subsubsection{The population dynamics model}

The population dynamics of one cohort was computed off-line according to the larval supply, growth and settlement processes, in order to simulate the spatial and temporal potential of pearl oyster recruitment. The larval supply depends on: (1) the broodstock density, with two scenarios: the reared oysters, $W_{r}$, and wild oysters, $W_{w}$ (Fig. A.1); (2) the mean sex-ratio, $\operatorname{Sr}(\%)$, estimated after Chavez-Villalba et al. (2011) according to the mean length of the broodstock (i.e., $L_{m r}$ for the reared broodstock and $L_{m w}$ for the wild broodstock), and (3) the fecundity, $F_{m}$ (oocyte ind. ${ }^{-1}$ ), depending on the mean length of the females oysters, itself estimated from the mean length of the broodstock: $F_{m}=\left(5.26 \mathrm{e}^{-7} \cdot \mathrm{L}_{\mathrm{m}}^{2.91}\right) / 15 \mathrm{e}^{-9}$ (Pouvreau et al., 2000b).

According to Andréfouët et al. (2016), the mean length of the wild broodstock was $13 \mathrm{~cm}$. For the reared oysters, we considered a 3-years old broodstock, with an average length of $10 \mathrm{~cm}$ (Pouvreau and Prasil, 2001).

The initial number of larvae released $N_{0}$, is computed for the two scenarios (i.e. reared and wild) in each model cell using:
$N_{0}=W \cdot S r \cdot F_{m}$

To simulate the larval life-history traits (i.e. dispersal, growth, mortality and settlement), this initial number of larvae $\left(N_{0}\right)$ was dispatched between the 12 particles released by model cell in the 3D dispersal model. Thus, each particle released from a grid cell containing adult oysters corresponded to a sub-population of larvae, submitted to an individual growth and to a mortality and settlement probability.

A standard exponential mortality model was applied to estimate the number of larvae at each time step following:

$N(t)=N_{0} e^{-M t}$

With $N(t)$ the number of larvae at time $(t)$ and $(M)$ the daily mortality rate, which was estimated at $0.2 \mathrm{~d}^{-1}$, and corresponded to the mortality rate estimation of most of the invertebrate larvae (Rumrill, 1990). By combining the number of larvae $(N)$ and the settlement probability $(P)$, the number of competent larvae $\left(N_{c}\right)$ was computed at each time step, in each of the sectors of the connectivity study (see below), such as:

$N c_{i}(t)=\sum_{p=1}^{p=n} N_{p i}(t) \cdot P_{p i}(t)$

with $N c_{i}(t)$, the number of competent larvae at time $(t)$ in the arrival sector $(i), N_{p i}(t)$ the total number of larvae bound to the particle $(p)$ at time $(t)$ in arrival sector $(i)$, with $(n)$ the total number of particles in arrival sector $(i)$, and $P_{p i}(t)$ the probability of fixing of the larvae bound to the particle $(p)$ at time $(t)$ in arrival sector $(i)$. At each time step, the larvae having reached the length threshold was considered ready to settle and remained at their position. The cumulated number of larvae settled in each arrival sector was computed. Results were expressed in number of larvae settled per hectare, by dividing the total number of settled larvae by the arrival sector surface. 


\subsection{Forcing variables}

\subsubsection{Physical forcing}

To model Ahe lagoon, four ranks of nesting were required: three shallow water levels to describe the open boundary conditions of the atoll model itself, including astronomical and meteorological tides i.e. Rank 0 for all the Polynesia ( $3 \mathrm{~km}$ grid). Rank 1 modelled the vicinity of Ahe and the nearby Manihi atolls ( $1 \mathrm{~km}$ grid) and Rank 2 provided a close-up on these two atolls (300 $\mathrm{m}$ grid). The third wider model was forced by the sea level coming out an harmonical composition deduced form the tidal wave components of the FES2004 atlas (Lyard et al., 2006). An inverse barometric correction estimated from pressure fields (ERA-Interim analysis: http://www.ecmwf.int/research/era/do/get/era-interim) was added to the previous sea level. The wind fields for the detailed lagoon model came from the same analysis with a 6-h time step at the closest Ahe lagoon grid point for the periods simulated (Fig. A.2).

\subsubsection{Food and temperature data}

The biophysical DEB model implied to get tridimensional forcing by Chl-a concentration and water temperature. Theses data came from field data previously described by Thomas et al. (2010a). Daily vertical profiles of temperature $\left({ }^{\circ} \mathrm{C}\right)$ and in vivo $\mathrm{Chl}-\mathrm{a}\left(\mu \mathrm{g} \mathrm{l^{-1 }}\right)$ were carried out with a multi-parameter probe (SBE S19Plus, Sea-Bird Electronics) at 12 locations distributed all over the lagoon. Data were collected during two 28 days periods: in April-May 2007 and February-March 2008.

The daily Chl-a concentration and temperature data were interpolated and extrapolated by using the inverse distance weighting (IDW) method in the boundaries of the lagoon rim and on the entire water column, by 1-m depth steps, in order to get forcing at the scale of the transport model. The IDW method assumed that the value at a non sampling point is the average of the overall data, weighted by the distance to the sample point considered, such as:

$C\left(S_{0}\right)=\sum_{i=1}^{N} \frac{\frac{1}{d_{i}^{2}} C\left(S_{i}\right)}{\sum_{i=1}^{N} \frac{1}{d_{i}^{2}}}$

with $C\left(S_{0}\right)$ the predicted value at point $\left(S_{0}\right), d_{i}$ the distance from $S_{0}$ to the sampled point $S_{i}$, N being the total number of sampling station and $C\left(S_{i}\right)$ the value recorded at sampling point $S_{i}$. All the calculations were made using the $R$ programming environment $(R$ Development Core Team, 2012).

\subsection{Modelling strategy}

We aimed to compare dispersal, growth performance and patterns of realized connectivity potential (i.e. after the settlement) of the pearl oyster larvae, for two measured biophysical conditions, in 2007 and 2008. In addition, the contribution of the reared and wild broodstocks to these patterns was estimated and compared. Finally, to estimate the consequences of the spatial heterogeneity of the food and thermal conditions, two scenarios were tested: one with the observed conditions and one with spatially homogenized conditions. For the later scenario, food and temperature were spatially averaged at a daily scale, in order to maintain the temporal variability while avoiding spatial heterogeneity.

As in Thomas et al. (2012b, 2014), the connectivity was synthesized by dividing the lagoon in 12 sectors, covering the entire lagoon surface, excluding shallow areas ( $<5 \mathrm{~m}$ depth) along the atoll rim (Fig. 1). At each time step, the realized connectivity pattern was computed by cumulating the number of larvae settled in the destination location $(d)$ coming from the spawning site $(s)$.

A sensitivity analysis was performed on the parameters with the greatest uncertainty: the broodstock mean lengths ( $L_{m r}$ and $L_{m w}$ ), the larval length standard deviation factor $\left(\sigma_{L}\right)$ and the larval mortality rate $(\mathrm{M})$. These parameters were modified by $\pm 10 \%$ and subsequent consequences on the settlement potential were computed by calculating a sensitivity index (SI) such as:

$S I=\frac{R_{S i}-R_{0}}{R_{0}} \cdot 100$

where $\left(R_{0}\right)$ is the predicted cumulated settlement potential (total number of larvae settled after 28 days of simulations) with the standard simulation and $\left(R_{s i}\right)$ the predicted cumulated settlement potential with a new parameter value.

\section{Results}

\subsection{Forcing variables}

Meteorological conditions were very close between the two studied periods, with averaged wind direction and speed of $89^{\circ}$ at $5.6 \mathrm{~m} \mathrm{~s}^{-1}$ and $86^{\circ}$ at $5.4 \mathrm{~m} \mathrm{~s}^{-1}$ for 2007 and 2008 , respectively (Fig. A.2). However, the two considered periods showed contrasting trophic conditions, with an overall average of $0.4 \pm 0.18 \mu \mathrm{g}_{\mathrm{Chl}-\mathrm{a}} \mathrm{L}^{-1}$ in 2007, versus $0.24 \pm 0.14 \mu \mathrm{g}_{\mathrm{Chl}-\mathrm{a}} \mathrm{L}^{-1}$ in 2008 (Fig. A.3a-c). Thermal conditions were also warmer in 2007 with $29.3 \pm 0.17{ }^{\circ} \mathrm{C}$ versus $28.6 \pm 0.19^{\circ} \mathrm{C}$ in 2008 (Fig. A.3b-d). At the scale of the Ahe atoll lagoon, the trophic conditions appeared heterogeneous and closely related to the bathymetry, with an increasing gradient toward deep and southwest waters (Fig. A.4 and A.5). Thermal conditions were less vertically-structured and the west-east gradient dominated, with warmer water in the southwest sector.

\subsection{Settlement potential}

The temporal variability (i.e. 2007 versus 2008) and spatial heterogeneity (real versus homogenized) of the environmental conditions, and the broodstock factor (i.e. reared versus wild), all led to significant differences in the settlement potential dynamics (Fig. 2). The final settlement densities with realistic conditions were 15,900 and 3950 oysters per ha for the reared and wild broodstock respectively in 2007 and 394 and 105 oysters per ha for the reared and wild broodstock respectively in 2008. In 2007, the settlement started earlier, with $10 \%$ of the final settlement density reached after 16 days, against 20 days in 2008 . Homogenized conditions led to higher settlement potential, with $+65 \%,+70 \%,+114 \%$ and $+115 \%$ after 28 days of simulations for the 4 scenarios (i.e., 2007 reared, 2007 wild, 2008 reared, 2008 wild, respectively), and lower spatial variability, with a coefficient of variation (i.e., standard deviation/ mean) of $45 \%, 50 \%, 34 \%$ and $35 \%$ for the realistic conditions against $10 \%, 11 \%, 7 \%, 8 \%$ for the homogenized conditions.

The cumulated settlement potential showed intra-lagoon spatial heterogeneity with differences depending on time (i.e. 2007 versus 2008) and space (real versus homogenized) environmental conditions (Fig. 3). Only slight differences were recorded between the spatial patterns of larval settlement coming from the wild and reared broodstocks. With 2007 realistic conditions, the central destination locations (DL) 6 and 9 showed the higher settlement potential, whereas the western DL 2 was highly promoted with the 2008 scenario. With homogenized 2007 conditions, the settlement increased in the western DLs and decreased in the eastern DLs. With the 2008 scenario, opposite consequences were found, with a decrease in the western DLs and an increase in the eastern DLs. 
2007 Reared

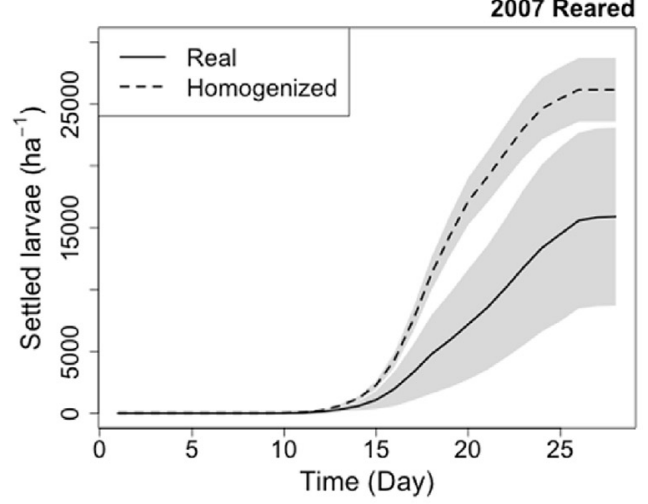

2008 Reared

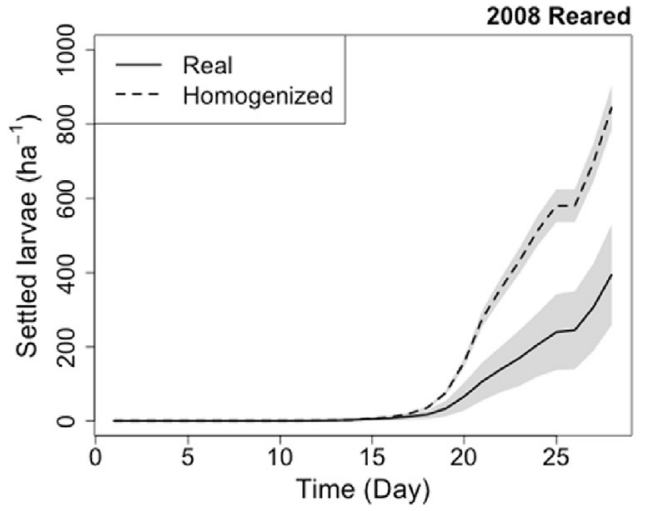

2007 Wild

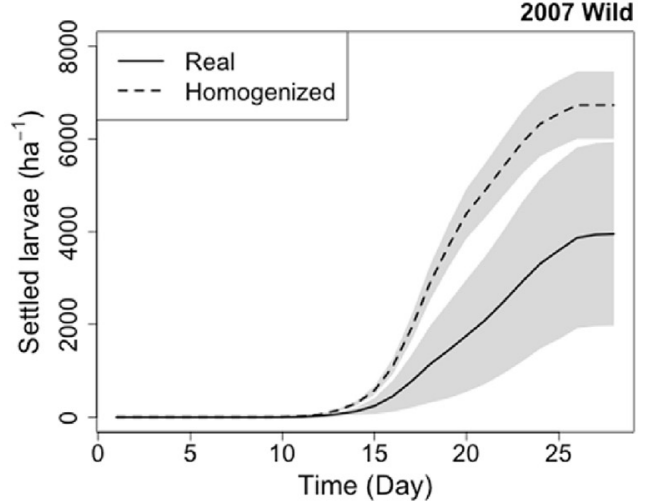

2008 Wild

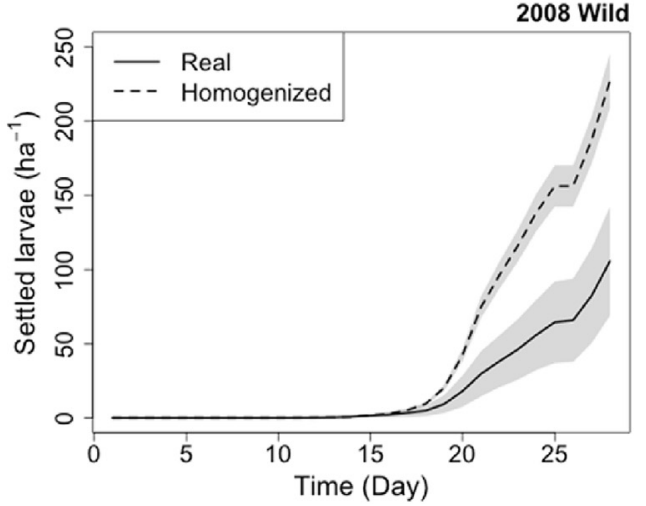

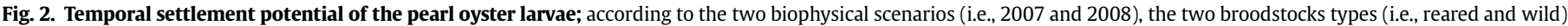

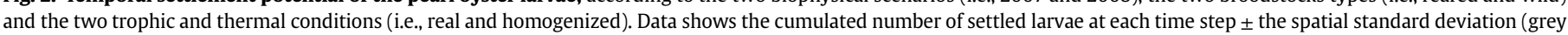
shading). Note the difference in Y-axis scale.

The contribution of the 12 spawning sites (SS) to the overall settlement after 28 days appeared quite similar between realistic conditions in 2007 and 2008 (Fig. 4): SS 7 and 8 were the largest contributors for the reared broodstock and SS 1 for the wild broodstock. However, with homogenized conditions, only slight differences were recorded in 2007 in the contribution pattern while in 2008 , the eastern SS had a higher contribution.

\subsection{Connectivity patterns}

The connectivity matrices gave a complete picture of the exchanges between lagoon sectors (Fig. 5). Beyond the absolute variability in settlement density described above, the two simulated periods exhibited different patterns of connectivity under realistic conditions, both for reared and wild broodstocks. Low selfrecruitment is suggested by the asymmetry along the diagonal.

The reared broodstock enriched in 2007 the central and eastern sectors, which were highly supplied by the spawning sector 7 (Fig. 5a). SS 7 also exhibited the higher retention potential. In 2008, settlement was more symmetric with more retention in the western sectors DL 2 and 3 (Fig. 5b). Spawning sectors 7 and 8 supplied most of the settled oysters all over the lagoon.

From the wild broodstock, in 2007 and 2008, the settlement was mostly sustained by the western SS 1 and, to a lesser extend by eastern SS 11 and 12, as observed in Fig. 4 (Fig. 5c-d). Differences between the 2007 and 2008 scenarios were the same as for the reared broodstock: eastern western DL were promoted in 2007 and 2008 respectively.

The differences achieved between connectivity matrices from the homogenized and the realistic environmental conditions, respectively, are shown in the form of connectivity matrix ratios (Fig. 6). These ratios were quite similar between the reared and wild broodstock scenarios. In 2007 , homogenization led to increase the settlement potential in the western sectors, with a high selfrecruitment in the DL 1 to 5 (Fig. 6a-c). In 2008, homogeneous conditions led to increase the contribution of the eastern sectors to the settlement in all sectors of the lagoon, except in western DL 1 and 2 (Fig. 6b-d).

\subsection{Sensitivity analysis}

The sensitivity of the model to three parameters was estimated: the broodstock mean length ( $L_{m r}$ and $\left.L_{m w}\right)$, the larval length standard deviation $\left(\sigma_{L}\right)$ and the larval mortality rate $(\mathrm{M})$. A $\pm 10 \%$ variation of these three parameters led to significant differences in the final settlement potential (Fig. 7). The only difference between the two environmental scenarios (2007 and 2008) was recorded for the larval length standard deviation parameter $\left(\sigma_{L}\right)$, whereas the sensitivity was the same for the two other parameters (broodstock mean length and mortality rate). Moreover, the effects appeared asymmetrical for these three parameters, with differences between $+10 \%$ and $-10 \%$.

In $2007,+10 \%$ in $\sigma_{L}$ led to $+66 \pm 6 \%$ in final settlement density and $-10 \%$ led to $-47 \pm 2 \%$ in final settlement density, whereas in $2008+10 \%$ or $-10 \%$ in $\sigma_{L}$ led to stronger effect with $+169 \pm 14 \%$ and $-73 \pm 1 \%$, respectively (Fig. $7 \mathrm{~b}-\mathrm{e}$ ). Just as for $\sigma_{L}$, sensitivity results were also asymmetrical for the broodstock mean length: $+10 \%$ increased the final settlement potential by $94 \pm 5 \%$ whereas $-10 \%$ decreased it by $53 \pm 1 \%$ (Fig. 7a-d). Similarly, 10\% increase or decrease of larval mortality rate yielded 

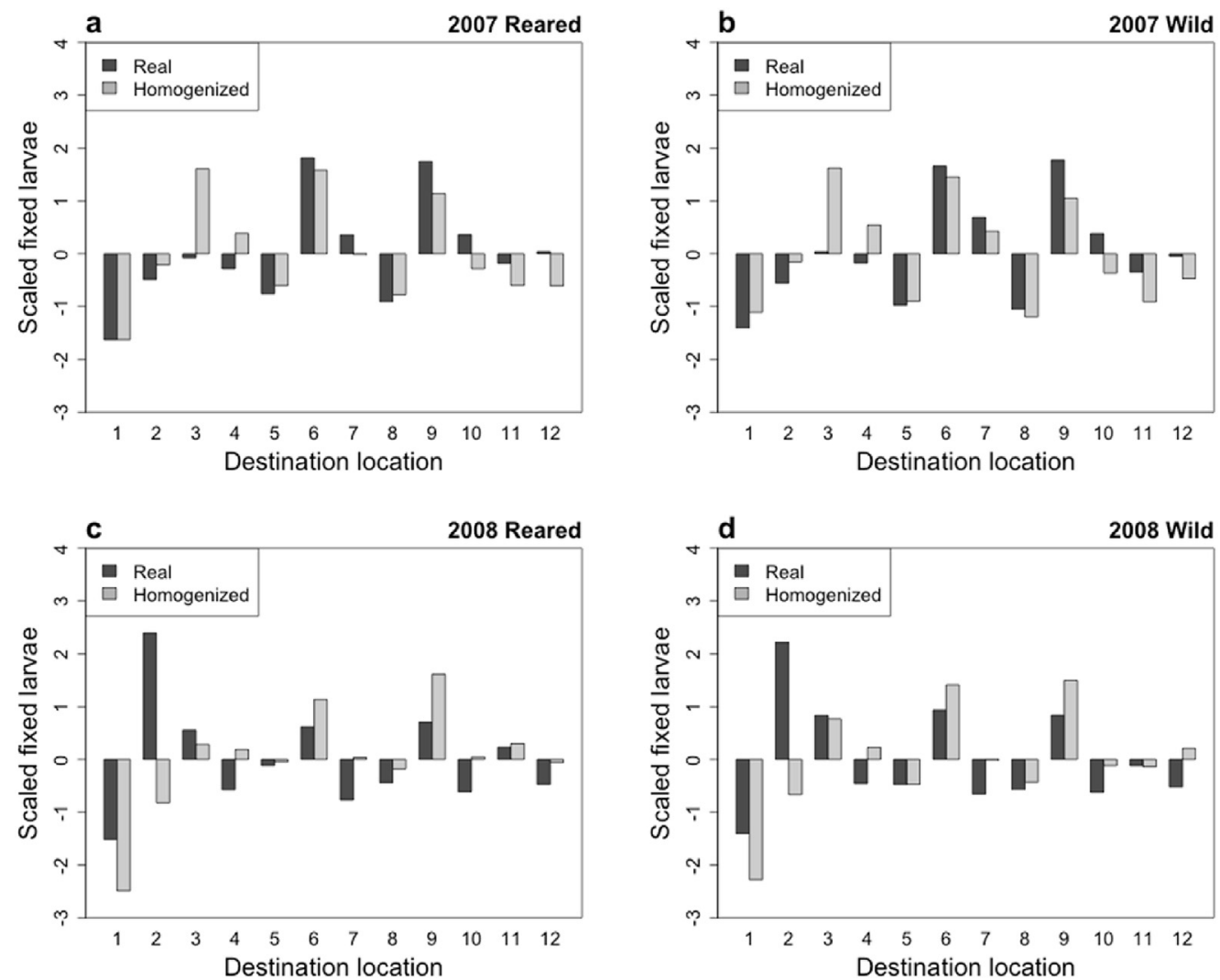

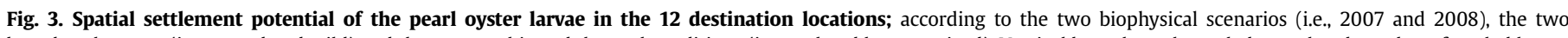

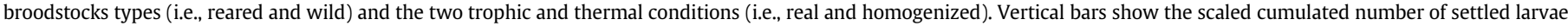
simulated after 28 days.

respectively $-41 \pm 1 \%$ and $+69 \pm 2 \%$ change in settlement potential (Fig. 7c-f).

\section{Discussion}

Biophysical models are increasingly used in population connectivity studies, including to estimate the respective contribution of biological and physical factors to benthic invertebrates population dynamics (Metaxas and Saunders, 2009). Here, we coupled a 3D larval transport model with a bioenergetics growth model to understand the consequences of environmental heterogeneity on pearl oyster larval development, settlement potential and subsequent intra-lagoon connectivity patterns. This work was the logical next step after several years of modelling which led to the calibration and validation of the models taken separately (Thomas et al., 2011, 2012b; Dumas et al., 2012). Both models have highlighted how biological and physical factors influence and can explain the heterogeneity in pearl oyster larval settlement. These factors included wind conditions, broodstock location and pelagic larval duration. However, without the dynamics of the larval lifehistory traits, we remained unable to estimate realistically the consequences of changing trophic and thermal conditions on the settlement patterns until now. Coupling a 3D transport model with a mechanistic growth model using 3D forcing data from in situ measurements provided the opportunity to tackle this challenge.

In vivo chlorophyll-a (Chl-a) is a good descriptor of the food of $P$. margaritifera larvae in the natural environment (Thomas et al., 2011). Nonetheless, phytoplankton composition in atoll lagoons may vary temporally and spatially (Charpy and Blanchot, 1998; Gonzalez et al., 1998; Thomas et al., 2010b; Charpy et al., 2012), and the same amount of Chl- $a$ may come from various panel of species, such as pico- or nano-phytoplankton, which are not equally ingested by the larvae. However, co-variations in the abundance of the phytoplankton communities have been shown consistently. Further investigation might be needed to exactly describe the larval physiology and possible shifts in nutrition preferences, but phytoplankton composition in atoll lagoons seems to be stable enough at our relevant spatial and temporal scales, so that total $C h l-a$ can be a relevant proxy of the trophic environment and its consequences on larval life-history traits.

Both spatial and temporal heterogeneity in trophic conditions proved to be determinant for the larval settlement potential, creating a range of spatially and temporally explicit patterns. However, we found a much higher temporal variability in potential recruitment than spatial variability. Averaged settlement potential was 40 times higher in 2007 than 2008 (19,853 larvae ha ${ }^{-1}$ versus 500 larvae ha ${ }^{-1}$, giving $4000 \%$ of variation), compared to the spatial coefficients of variation of $46 \%$ and $34 \%$ in 2007 and 2008 respectively. This temporal difference is explained by more favourable trophic conditions in 2007, with an overall average of $0.4 \pm 0.18 \mu \mathrm{g}_{\mathrm{Chl}-\mathrm{a}} \mathrm{L}^{-1}$ against $0.24 \pm 0.14 \mu \mathrm{g}_{\mathrm{Chl}-\mathrm{a}} \mathrm{L}^{-1}$ in 2008 . Thermal conditions were also warmer in 2007, but for both years the range of conditions were close to the optimal range of the black-lip pearl oyster larval development (Doroudi et al., 1999). The two contrasted conditions found in 2007 and 2008 in fact provided a representative view of the range of seasonal, inter-annual and inter-lagoon variability recorded in phytoplankton concentration in Polynesian atoll lagoons (Charpy and Blanchot, 1998; Pagès et al., 2001; Thomas et al., 2010b). Only completely closed atoll lagoons like Taiaro $\left(1.17 \mu \mathrm{g}_{\mathrm{Chl}-\mathrm{a}} \mathrm{L}^{-1}\right.$ recorded), and transient bloom events 

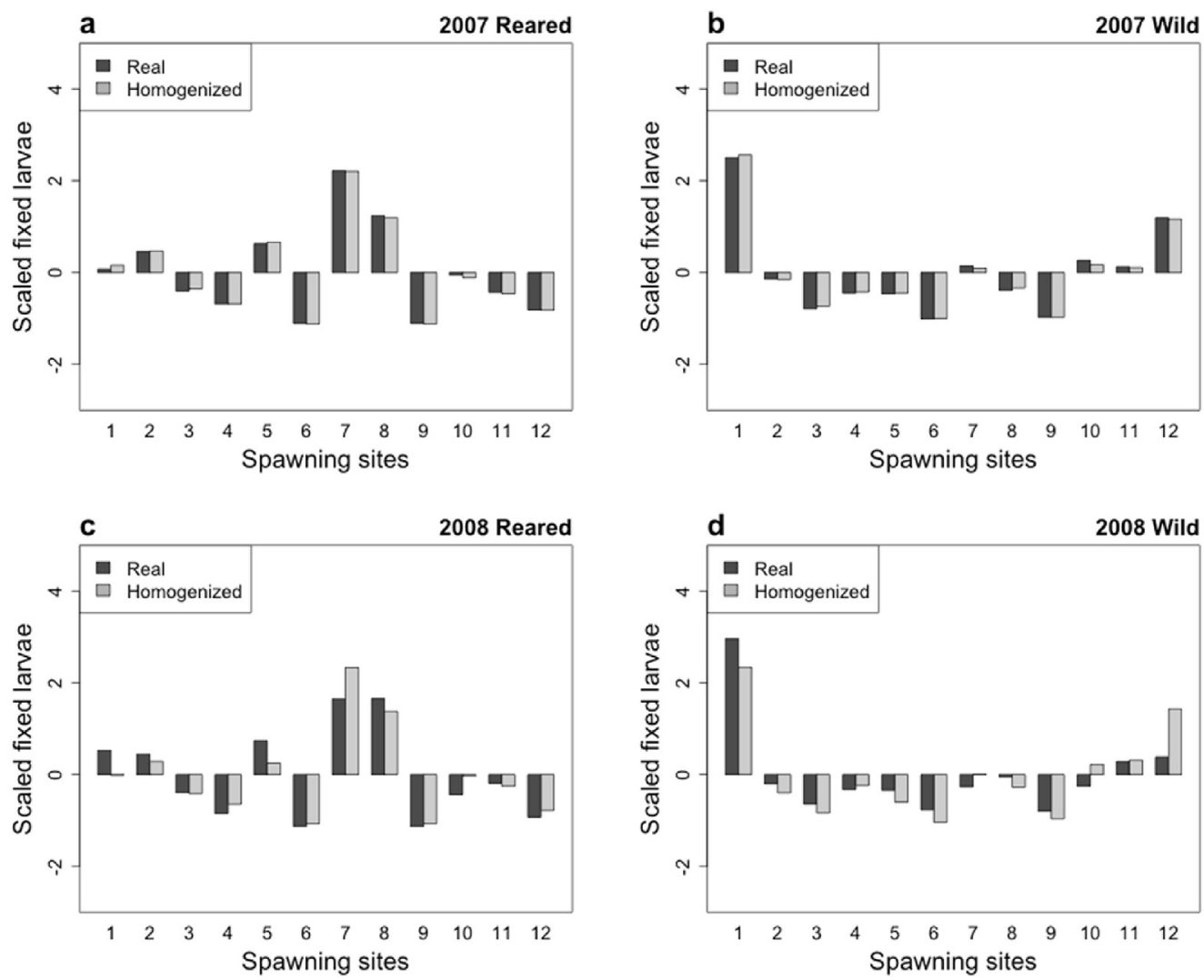

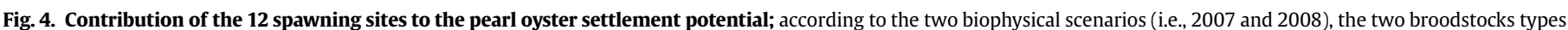

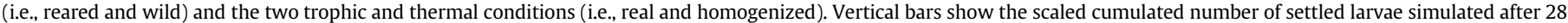
days, coming from each of the 12 spawning sites.

may provide conditions outside our studied range.

Differences in larval connectivity patterns between the realistic and homogeneous trophic and thermal scenarios highlighted the significant effect that a heterogeneous environment can have on recruitment. Settlement densities increased by a factor between 1.6 and 2.2 from heterogeneous (realistic) to homogeneous conditions. The overall population of larvae thus experiences a growth deficit during their pelagic life history, when the environmental conditions are heterogeneous. High-food concentrations are found in the bottom layers (as shown in Fig A4). Due to the combination of the water circulation and behaviour, larvae seem to stay less time in these bottom layers and more time in "poor" waters, which could lead to starving conditions. This observation has strong implication for monitoring: if heterogeneous and homogeneous conditions had provided similar results, then only one monitoring point in the lagoon would be sufficient to represent the overall lagoon characteristics. This is not the case, as one could have expected from the actual rates of collecting experienced by farmers. Our results also imply that it is necessary to closely monitor, or model, at fairly high-resolution changes in environmental conditions to be able to accurately and finely predict pearl oyster population dynamics.

Patterns of realized connectivity showed the potential differences in the contribution of each lagoon sector to the recruitment. The connectivity matrices with homogenized conditions suggested that eastern wind in 2007 promoted retention and thus selfrecruitment, whereas east-north-eastern winds observed in 2008 increased east-west transfers. But these differences were small in the present case, mainly due to very similar meteorological conditions between the two studied periods (see Fig. S2). Previous results have shown that drastic wind differences are needed to strongly modify the connectivity patterns (Thomas et al., 2014). We can thus argue that most of the differences in the patterns of realized connectivity are due to biological factors, associated with the trophic heterogeneity.

The broodstock location and its characteristics (i.e., individual mean length and related sex-ratio and fecundity) significantly affected settlement potential at the scale of the Ahe lagoon. The reared broodstock contributed to settlement four times more than the wild broodstock, regardless of the environmental conditions. $P$. margaritifera is a protandrous hermaphrodite, male in early life and female later on, with sex ratio being balanced by age (ChavezVillalba et al., 2011). Considering a mean length of 100 and $130 \mathrm{~mm}$ for respectively the reared and wild broodstock, the corresponding sex-ratios were 0.06 and 0.16 , fecundity was 23 millions and 50 millions oocytes per female, with a total of 1.4 millions and 0.2 millions females for the reared and wild broodstocks respectively. Thus, with an older aging population, the wild pearl oysters support $20 \%$ of the spatfall with only $12.5 \%$ of the female population. The sensitivity analysis showed the strong effect of the broodstock length, with a $100 \%$ spatfall increase with adults only $10 \%$ larger. This result has immediate consequences for pearl oyster farming management. Indeed, during the last decades, reared oysters were gradually grafted at smaller and smaller length, and less supplementary graft were done with the same oyster. Indeed, one oyster giving pearls of good quality may be grafted from 1 to 4 times, with nucleus of increasing size, which gives pearls of increasing size. Nonetheless, due to the decrease of oyster growth rate with increasing size, oysters of large size take much more time to 

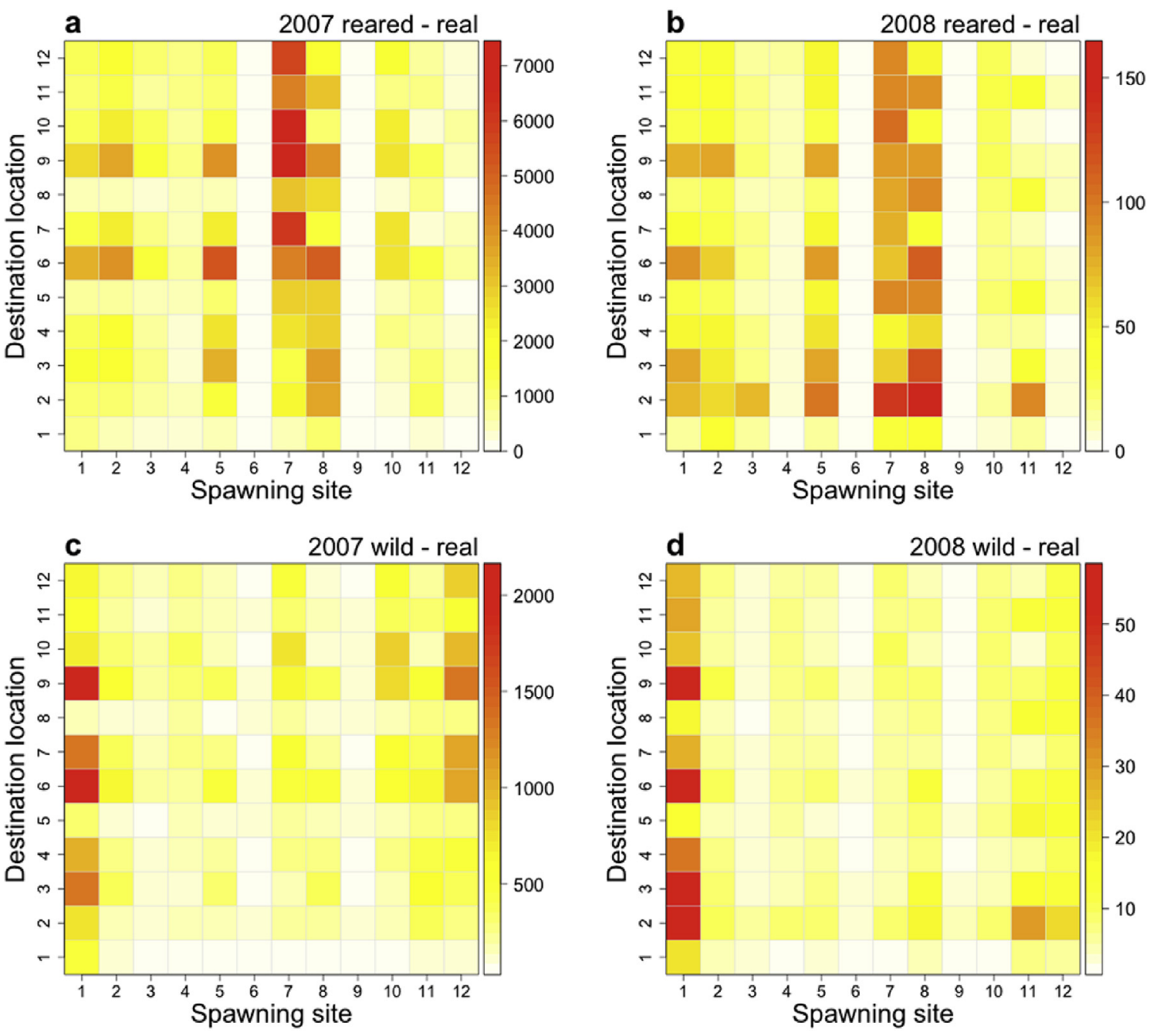

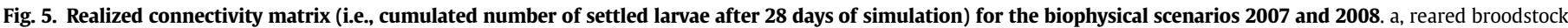

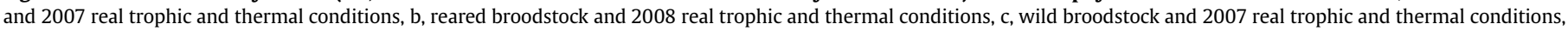
$\mathrm{d}$, wild broodstock and 2008 real trophic and thermal conditions.

produce a pearl. That is why producers are more focused on fast growing oysters, which produce pearls faster. This reduces the duration of the production process and increase productivity. But this practice eventually decreased the overall length of cultured oysters, and consequently decreased the female ratio, fecundity and ultimately the subsequent recruitment potential. If an evolution of the farming practices seems economically and politically compromised, spawning sanctuaries could be created instead. Sanctuaries are effective for population replenishment (Schulte et al., 2009), and they may incidentally promote pearl oyster recruitment. Cultured oysters, which are discarded and killed right after the pearl harvest, could be used instead to create sanctuaries. However, the creation of sanctuaries may warrant further investigation considering their origins, since there are evidences that the genetic pool of $P$. margaritifera in the Tuamotu Archipelago have been impacted by inter-atoll translocation (Lemer and Planes, 2012). The modelling tools used here would indicate the best sectors for these sanctuaries if they also aim to enhance professional spat collection. The stock replenishment strategy will also on the long term contribute to the maintenance of a wild population, which is in many lagoons now marginal compared to the reared one (Andréfouët et al., 2016).
Just as for larval development, availability of food affects the adult reproductive efficiency. Indeed, $P$. margaritifera is an opportunistic species with very low energy storage abilities. It invests all surplus of energy into its reproduction, and spawning are tightly linked to variation of food availability (Pouvreau et al., 2000a; Fournier et al., 2012). The spatial and temporal patterns of pearl oyster reproduction may thus lead to contrasting patterns of recruitment. A mechanistic and spatially explicit understanding of the pearl oyster reproductive output clearly warrants further investigation. For this, the development and parameterization of a DEB model for the adult stage of the pearl oyster will be a next priority to complete our integrative modelling strategy. A first approach has been developed by Fournier (2011), and will need to be completed, validated and coupled with the 3D model used here.

The inter-individual larval growth and mortality rates were also important drivers of the final recruitment results. Estimating larval mortality rate and inter-individual growth variability is extremely challenging in the field, because tracking dispersing larvae is not an easy task. Larval mortality of benthic species is a major player on larval recruitment potential and population dynamics (Cowen et al., 2000; Ellien et al., 2004; Levin, 2006). This research confirms this. The main source of mortality is often 

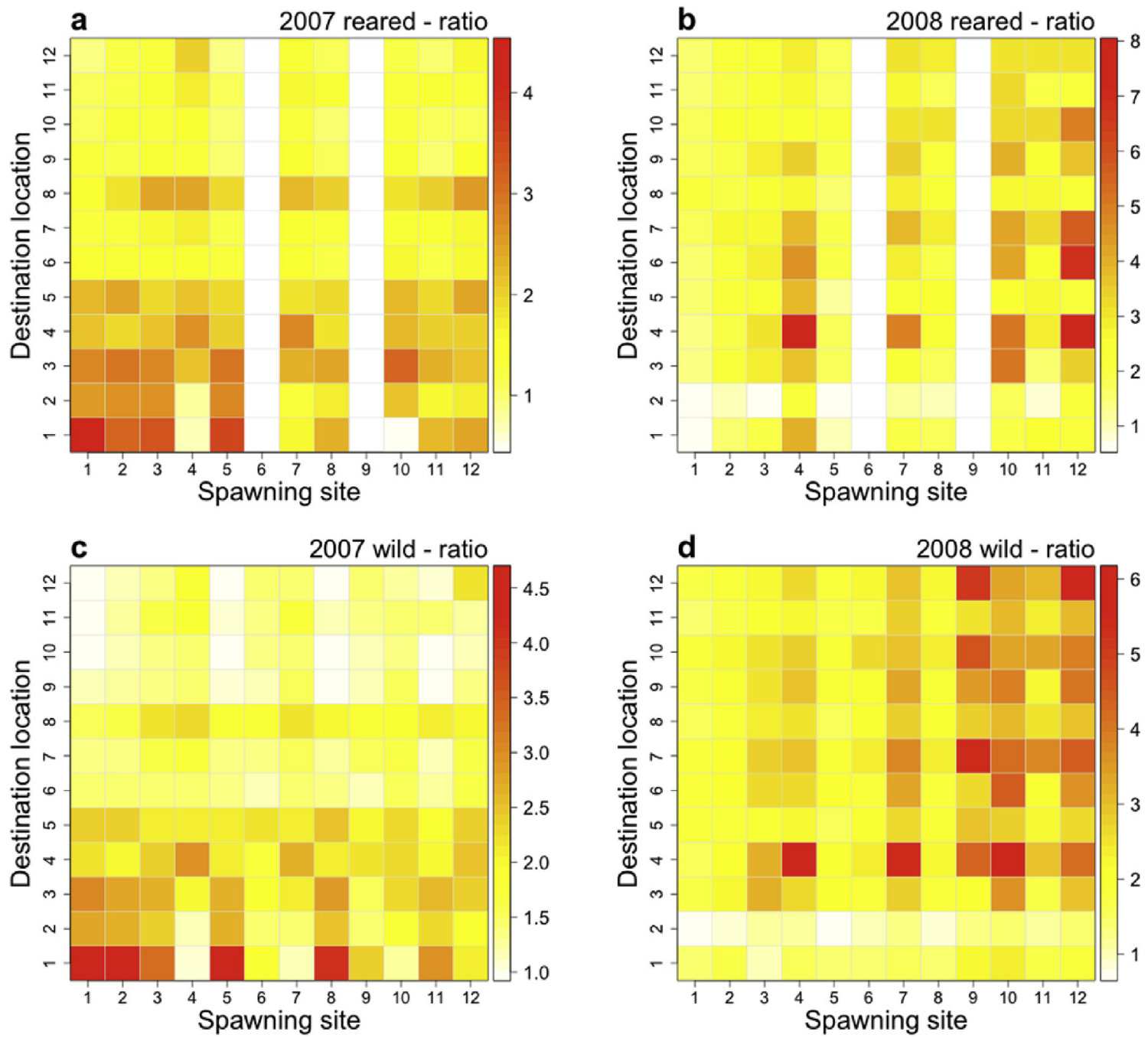

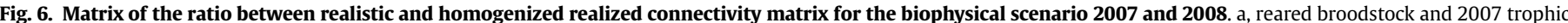

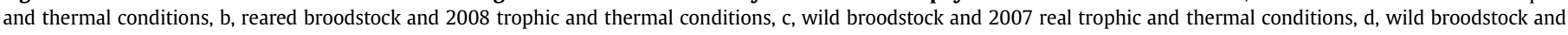
2008 trophic and thermal conditions.

assumed to be predation, but starvation and physiological stress due to salinity and/or temperature may also contribute (Hofmann et al., 2004). Here, the mortality rate was fixed, but a sensitivity analysis clarified the potential consequences of larval mortality on recruitment potential. The DEB model provides a mechanistic framework giving the possibility to take into account starvation and physiological stress that lead to death (Kooijman, 2010). However, further investigations will be needed to properly calibrate the model. Future field studies will need to use recent tools to measure larval mortality, especially to assess the predation factor (White et al., 2014).

Finally, individual-based-modelling (IBM) approaches offers an interesting perspective to take into account inter-individual heterogeneity and estimate the consequences at the population level (DeAngelis and Mooij, 2005). Our results suggest a significant effect of larval population growth variability, mainly due to the food limitation, which slowed growth. Only largest larvae were able to settle. Several studies successfully developed IBM-DEB approaches to model species population dynamics (Martin et al., 2012; Pethybridge et al., 2013; Saraiva et al., 2014). An IBM-DEB approach including a mechanistic and spatially explicit understanding of the mortality process would be a major improvement of this work, towards a better understanding and modelling of blacklip pearl oyster population dynamics.

\section{Conclusion}

The biophysical modelling approach presented here to simulate Pinctada margaritifera recruitment potential according to realistic environmental and population factors identified and quantified the significant effect of trophic resource. We found that 40 times more spatfall can be recruited between a food-abundant period and a less abundant period. We show how the spatial heterogeneity of trophic resources penalized larval growth, and modified the intra-lagoon connectivity pattern. Future priorities point to the integration of biogeochemical models able to accurately provide 3D fields of food resource for long-term application and inter-site comparison (Pinazo et al., 2004; Baklouti et al., 2006). Finally, the influence of the broodstock location and its intrinsic characteristics (i.e. sexratio, fecundity) on recruitment potential is also clarified. This research provides clear recommendations for lagoon management and enhanced spat collection practices, in particular the relevance of setting sanctuaries in adequate locations that can be identified from connectivity matrices. 

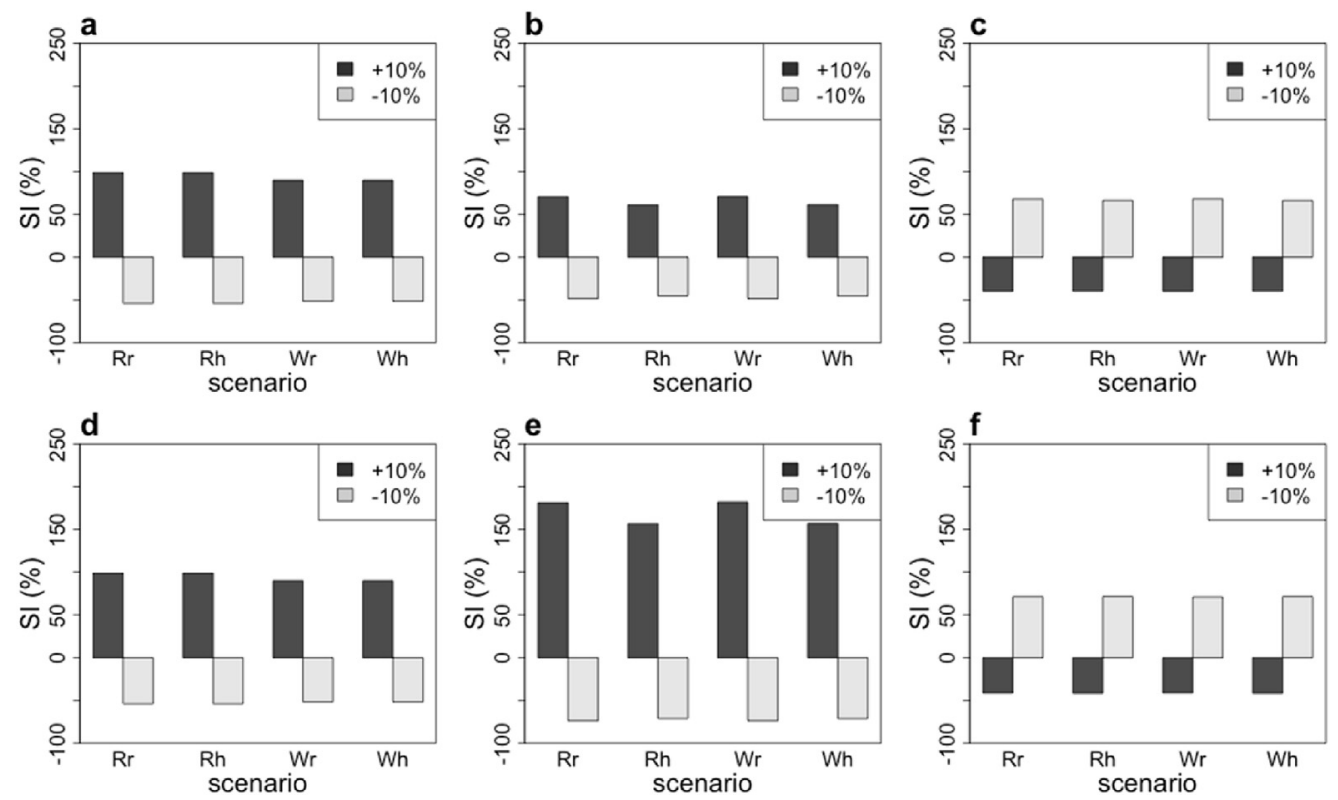

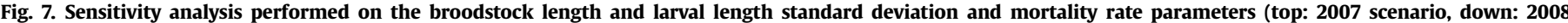

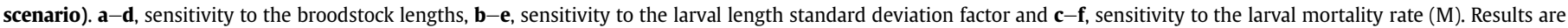
shown for the reared broodstock and real ( $\mathrm{Rr}$ ) and homogenized ( $\mathrm{Rh}$ ) conditions and for the wild broodstock and real (Wr) and homogenized (Wh) conditions.

\section{Acknowledgements}

This study was funded by the Agence Nationale de la Recherche (ANR, www.agence-nationale-recherche.fr, grant ANR-11-AGRO006), as part of the POLYPERL project (www.polyperl.org). The authors' research in Ahe atoll has also been supported since several years by the Direction des Ressources Marines de Polynésie française. We also acknowledge the support of the R/V Alis and its crew during our research in Ahe atoll (POLYPERL campaign). This is ENTROPIE contribution 107.

\section{Appendix A. Supplementary data}

Supplementary data related to this article can be found at http:// dx.doi.org/10.1016/j.ecss.2016.03.010.

\section{References}

Andréfouët, S., Charpy, L., Lo-Yat, A., Lo, C., 2012. Recent research for pearl oyster aquaculture management in French Polynesia. Mar. Pollut. Bull. 65, 407-414.

Andréfouët, S., Claereboudt, M., Matsakis, P., Pagès, J., Dufour, P., 2001. Typology of atoll rims in Tuamotu Archipelago (French Polynesia) at landscape scale using SPOT HRV images. Int. J. Remote Sens. 22, 987-1004.

Andréfouët, S., Thomas, Y., Dumas, F., Lo, C., 2016. Revisiting wild stocks of black lip oyster Pinctada margaritifera in the Tuamotu Archipelago: the case of Ahe and Takaroa atolls and implications for the cultured pearl industry. Estuar. Coast. Shelf Sci. 182, 243-253.

Andréfouët, S., Thomas, Y., Lo, C., 2014. Amount and type of derelict gear from the declining black pearl oyster aquaculture in Ahe atoll lagoon, French Polynesia. Mar. Pollut. Bull. 83, 224-230.

Baklouti, M., Faure, V., Pawlowski, L., Sciandra, A., 2006. Investigation and sensitivity analysis of a mechanistic phytoplankton model implemented in a new modular numerical tool (Eco3M) dedicated to biogeochemical modelling. Prog. Oceanogr. 71, 34-58.

Charpy, L., Blanchot, J., 1998. Photosynthetic picoplankton in French Polynesian atoll lagoons: estimation of taxa contribution to biomass and production by flow cytometry. Mar. Ecol. Prog. Ser. 162, 57-70.

Charpy, L., Rodier, M., Fournier, J., Langlade, M.-J., Gaertner-Mazouni, N., 2012. Physical and chemical control of the phytoplankton of Ahe lagoon, French Polynesia. Mar. Pollut. Bull. 65, 471-477.

Chavez-Villalba, J., Soyez, C., Huvet, A., Gueguen, Y., Lo, C., Le Moullac, G., 2011. Determination of gender in the pearl oyster Pinctada margaritifera. J. Shellfish Res. 30, 231-240.

Cowen, R.K., Lwiza, K.M.M., Sponaugle, S., Paris, C.B., Olson, D.B., 2000. Connectivity of marine populations: open or closed? Science 287, 857-859.

DeAngelis, D.L., Mooij, W.M., 2005. Individual-based modeling of ecological and evolutionary processes. Annu. Rev. Ecol. Evol. Syst. 36, 147-168.

Doroudi, M.S., Southgate, P.C., Mayer, R.J., 1999. The combined effects of temperature and salinity on embryos and larvae of the black-lip pearl oyster, Pinctado margaritifera (L.). Aquac. Res. 30, 271-277.

Dumas, F., Le Gendre, R., Thomas, Y., Andréfouët, S., 2012. Tidal flushing and wind driven circulation of Ahe atoll lagoon (Tuamotu Archipelago, French Polynesia) from in situ observations and numerical modelling. Mar. Pollut. Bull. 65, 425-440.

Eckman, J.E., 1996. Closing the larval loop: linking larval ecology to the population dynamics of marine benthic invertebrates. J. Exp. Mar. Biol. Ecol. 200, 207-237.

Ellien, C., Thiébaut, E., Dumas, F., Salomon, J.-C., Nival, P., 2004. A modelling study of the respective role of hydrodynamic processes and larval mortality on larval dispersal and recruitment of benthic invertebrates: example of Pectinaria koren (Annelida: polychaeta) in the Bay of Seine (English Channel). J. Plankton Res. 26, 117-132.

Fournier, J., 2011. Alimentation et déterminisme environnemental de la reproduction des huîtres perlières $P$. margaritifera sur l'atoll d'Ahe (Archipel des Tuamotu, Polynésie Française). phD thesis. Université de Polynésie Française, 154 pp.

Fournier, J., Levesque, E., Pouvreau, S., Pennec, M.L., Le Moullac, G., 2012. Influence of plankton concentration on gametogenesis and spawning of the black lip pearl oyster Pinctada margaritifera in Ahe atoll lagoon (Tuamotu archipelago French polynesia). Mar. Pollut. Bull. 65, 463-470.

Gonzalez, J.M., Torréton, J.-P., Dufour, P., Charpy, L., 1998. Temporal and spatial dynamics of the pelagic microbial food web in an atoll lagoon. Aquat. Microb. Ecol. 16, 53-64.

Hinrichsen, H.-H, Dickey-Collas, M., Huret, M., Peck, M.A., Vikebø, F.B., 2011. Evaluating the suitability of coupled biophysical models for fishery management. ICES J. Mar. Sci. J. du Cons. 68, 1478-1487.

Hofmann, E.E., Powell, E.N., Bochenek, E.A., Klinck, J.M., 2004. A modelling study of the influence of environment and food supply on survival of Crassostrea gigas larvae. ICES J. Mar. Sci. 61, 596-616.

Kim, C.-K., Park, K., Powers, S.P., 2013. Establishing restoration strategy of eastern Oyster via a coupled biophysical transport model. Restor. Ecol. 21, 353-362.

Kim, C.K., Park, K., Powers, S.P., Graham, W.M., Bayha, K.M., 2010. Oyster larval transport in coastal Alabama: dominance of physical transport over biological behavior in a shallow estuary. J. Geophys. Res. 115, C10019.

Kooijman, S.A.L.M., 2010. Dynamic Energy Budget Theory for Metabolic Organisation. Cambridge University Press, Cambridge.

Lazure, P., Dumas, F., 2008. An external-internal mode coupling for a 3D hydrodynamical model for applications at regional scale (MARS). Adv. Water Resour. 31, 233-250.

Lemer, S., Planes, S., 2012. Translocation of wild populations: conservation implications for the genetic diversity of the black-lipped pearl oyster Pinctada margaritifera. Mol. Ecol. 21, 2949-2962.

Levin, L.A., 2006. Recent progress in understanding larval dispersal: new directions and digressions. Integr. Comp. Biol. 46, 282-297. 
Lyard, F., Lefevre, F., Letellier, T., Francis, O., 2006. Modelling the global ocean tides: modern insights from FES2004. Ocean. Dyn. 56, 394-415.

Martin, B.T., Zimmer, E.I., Grimm, V., Jager, T., 2012. Dynamic Energy Budget theory meets individual-based modelling: a generic and accessible implementation. Methods Ecol. Evol. 3, 445-449.

Metaxas, A., Saunders, M., 2009. Quantifying the "bio-" components in biophysical models of larval transport in marine benthic invertebrates: advances and pitfalls. Biol. Bull. 216, 257-272.

Nicolle, A., Dumas, F., Foveau, A., Foucher, E., Thiébaut, E., 2013. Modelling larva dispersal of the king scallop (Pecten maximus) in the English Channel: examples from the bay of Saint-Brieuc and the bay of Seine. Ocean. Dyn. 63, 661-678.

North, E.W., Schlag, Z., Hood, R.R., Li, M., Zhong, L., Gross, T., Kennedy, V.S., 2008. Vertical swimming behavior influences the dispersal of simulated oyster larvae in a coupled particle-tracking and hydrodynamic model of Chesapeake Bay. Mar. Ecol. Prog. Ser. 359, 99-115.

Pagès, J., Andrefouët, S., Delesalle, B., Prasil, V., 2001. Hydrology and trophic state in Takapoto Atoll lagoon: comparison with other Tuamotu lagoons. Aquat. Living Resour. 14, 183-193.

Pethybridge, H., Roos, D., Loizeau, V., Pecquerie, L., Bacher, C., 2013. Responses of European anchovy vital rates and population growth to environmental fluctuations: an individual-based modeling approach. Ecol. Model. 250, 370-383.

Pinazo, C., Bujan, S., Douillet, P., Fichez, R., Grenz, C., Maurin, A., 2004. Impact o wind and freshwater inputs on phytoplankton biomass in the coral reef lagoon of New Caledonia during the summer cyclonic period: a coupled threedimensional biogeochemical modeling approach. Coral Reefs 23, 281-296.

Pineda, J., 2000. Linking larval settlement to larval transport: assumption, potentials, and pitfalls. Oceanogr. East. Pac. 1, 84-105.

Pineda, J., Reyns, N., Starczak, V., 2009. Complexity and simplification in understanding recruitment in benthic populations. Popul. Ecol. 51, 17-32.

Pouvreau, S., Bacher, C., Héral, M., 2000a. Ecophysiological model of growth and reproduction of the black pearl oyster, Pinctada margaritifera: potential applications for pearl farming in French Polynesia. Aquaculture 186, 117-144.

Pouvreau, S., Gangnery, A., Tiapari, J., Lagarde, F., Garnier, M., Bodoy, A., 2000b. Gametogenic cycle and reproductive effort of the tropical blacklip pearl oyster Pinctada margaritifera (Bivalvia: pteriidae), cultivated in Takapoto atoll (French Polynesia). Aquat. Living Resour. 13, 37-48.
Pouvreau, S., Prasil, V., 2001. Growth of the black-lip pearl oyster, Pinctada margaritifera, at nine culture sites of French Polynesia: synthesis of several sampling designs conducted between 1994 and 1999. Aquat. Living Resour. 14, 155-163.

R Development Core Team, 2012. R: a Language and Environment for Statistical Computing. R Foundation for Statistical Computing, Vienna, Austria. http:// www.R-project.org/.

Rumrill, S.S., 1990. Natural mortality of marine invertebrate larvae. Ophelia 32, 163-198.

Saraiva, S., van der Meer, J., Kooijman, S.A.L.M., Ruardij, P., 2014. Bivalves: from individual to population modelling. J. Sea Res. 94, 71-83.

Schulte, D.M., Burke, R.P., Lipcius, R.N., 2009. Unprecedented restoration of a native oyster metapopulation. Science 325, 1124-1128.

Thomas, Y., Dumas, F., Andréfouët, S., 2014. Larval dispersal modeling of pearl oyster Pinctada margaritifera following realistic environmental and biological forcing in ahe atoll lagoon. PLoS One 9, e95050.

Thomas, Y., Garen, P., Bennett, A., Le Pennec, M., Clavier, J., 2012a. Multi-scale distribution and dynamics of bivalve larvae in a deep atoll lagoon (Ahe, French Polynesia). Mar. Pollut. Bull. 65, 453-462.

Thomas, Y., Garen, P., Courties, C., Charpy, L., 2010a. Spatial and temporal variability of the pico- and nanophytoplankton and bacterioplankton in a deep Polynesian atoll lagoon. Aquat. Microb. Ecol. 59, 89-101.

Thomas, Y., Garen, P., Courties, C., Charpy, L., 2010b. Spatial and temporal variability of the pico- and nanophytoplankton and bacterioplankton in a deep Polynesian atoll lagoon. Aquat. Microb. Ecol. 59, 89-101.

Thomas, Y., Garen, P., Pouvreau, S., 2011. Application of a bioenergetic growth model to larvae of the pearl oyster Pinctada margaritifera L. J. Sea Res, 66, 331-339.

Thomas, Y., Le Gendre, R., Garen, P., Dumas, F., Andréfouët, S., 2012b. Bivalve larvae transport and connectivity within the Ahe atoll lagoon (Tuamotu Archipelago), with application to pearl oyster aquaculture management. Mar. Pollut. Bull. 65, 441-452.

Visser, A.W., 1997. Using random walk models to simulate the vertical distribution of particles in a turbulent water column. Mar. Ecol. Prog. Ser. 158, 275-281.

White, J.W., Morgan, S.G., Fisher, J.L., 2014. Planktonic larval mortality rates are lower than widely expected. Ecology 95, 3344-3353. 